\title{
Malignant Melanoma on a Thermal Burn Scar with an Interval of More Than 70 Years
}

\author{
Shusuke Uchida Naoki Oiso Kuriko Shiga Tomohiko Narita \\ Akira Kawada \\ Department of Dermatology, Kindai University Faculty of Medicine, Osaka-Sayama, Japan
}

\section{Keywords}

Malignant melanoma $\cdot$ Thermal burn scar $\cdot$ Management $\cdot$ Dermoscopy

\begin{abstract}
Cases of malignant melanoma on thermal burn scars have occasionally been reported. We report a 78-year-old Japanese female with malignant melanoma on a thermal burn scar with an interval of more than 70 years. Our case reemphasizes the importance of regular examinations in persons with thermal burn scars.

(C) 2016 The Author(s) Published by S. Karger AG, Basel
\end{abstract}

\section{Introduction}

Cases of malignant melanoma on thermal burn scars have occasionally been reported [1-4]. Multiple malignant melanomas can arise on a thermal burn scar at different time points [3]. Furthermore, malignant melanoma and squamous cell carcinoma can concurrently arise on the thermal burn scar as well as on the areas treated with skin grafts [1, 4]. Here, we describe the case of a 78-year-old Japanese female with malignant melanoma on a thermal burn scar with an interval of more than 70 years. 


\section{Case Reports in Dermatology}

\section{Case Report}

A 78-year-old Japanese woman with dementia was referred to us with an asymptomatic blackish tumor on the right forehead. The right forehead had been deeply burnt thermally at the age of 5 years. A pigmented area had emerged on the scar 7 months previous to presentation. It had gradually increased in size and became darker in color. Physical examination revealed an asymptomatic blackish tumor with central ulceration, $30 \times 29 \mathrm{~mm}$ in size, on the thermal burn scar of the right forehead (fig. 1a). Dermoscopy showed a multicomponent pattern: irregular dots and globules, as well as blue-whitish veils and dermoscopic islands (fig. 1b).

A biopsy was taken from the blackish tumor. Atypical cells were found in the epidermis and the dermis (fig. 1c, d). The cells showed morphologically irregular sizes and shapes and large hyperchromatic nuclei with pale cytoplasms (fig. 1d). On the periphery, the atypical cells were located in the epidermis. Immunohistochemical staining of the tumor cells was positive for melan-A, S-100 and HMB-45. Positron emission tomography detected no metastatic lesions. A palliative excision with a 5-mm margin and a cover with the artificial dermis were done after agreement with the patient's relatives. Breslow's tumor thickness was 5 $\mathrm{mm}$. An adjuvant therapy with locoregional interferon- $\beta$ was subsequently performed. No signs of local recurrence or metastasis have been detected in the 10 months since the operation.

\section{Discussion}

Kowal-Vern and Criswell [1] summarized 23 cases of malignant melanoma and 5 cases with concomitant presence of squamous cell carcinoma and malignant melanoma. They showed the long latency period from the age of burn to the age when malignant melanoma was diagnosed ( $41 \pm 26$ years in the 23 cases with malignant melanoma only, and $48 \pm 13$ years in the 5 cases with squamous cell carcinoma and malignant melanoma). The long latency period was reemphasized in this case with an interval of more than 70 years. Periodical and very long follow-up of thermal burn scars represent a valid prophylactic option to avoid neoplastic proliferation even if the tumor appears [2].

\section{Statement of Ethics}

The patient gave written informed consent.

\section{Disclosure Statement}

The authors have no financial disclosures and no conflicts of interest. 


\section{Case Reports in Dermatology}

\section{References}

1 Kowal-Vern A, Criswell BK: Burn scar neoplasms: a literature review and statistical analysis. Burns 2005;31:403-413.

2 Ribero S, Grassi M, Caliendo V, Lauro D, Macripò G: Melanoma arising on a scar 10 years after a burn: management and review of the literature. Ann Plast Surg 2012;69:27-29.

-3 Atzeni M, Serratore F, Zaccheddu F, Buosi M, Nemolato S, Ribuffo D: Multiple melanoma arising on a burn scar and extensive sunburn: a case report and a review of the literature. Melanoma Res 2009;19:195-198.

-4 Hiscutt EL, Adams JR, Ryan JM, Langtry JA, Natarajan S: Atypical fibroxanthoma, lentigo maligna melanoma and squamous cell carcinoma arising in the site of a thermal burn treated with skin grafts. Br J Oral Maxillofac Surg 2009;47:157-158.
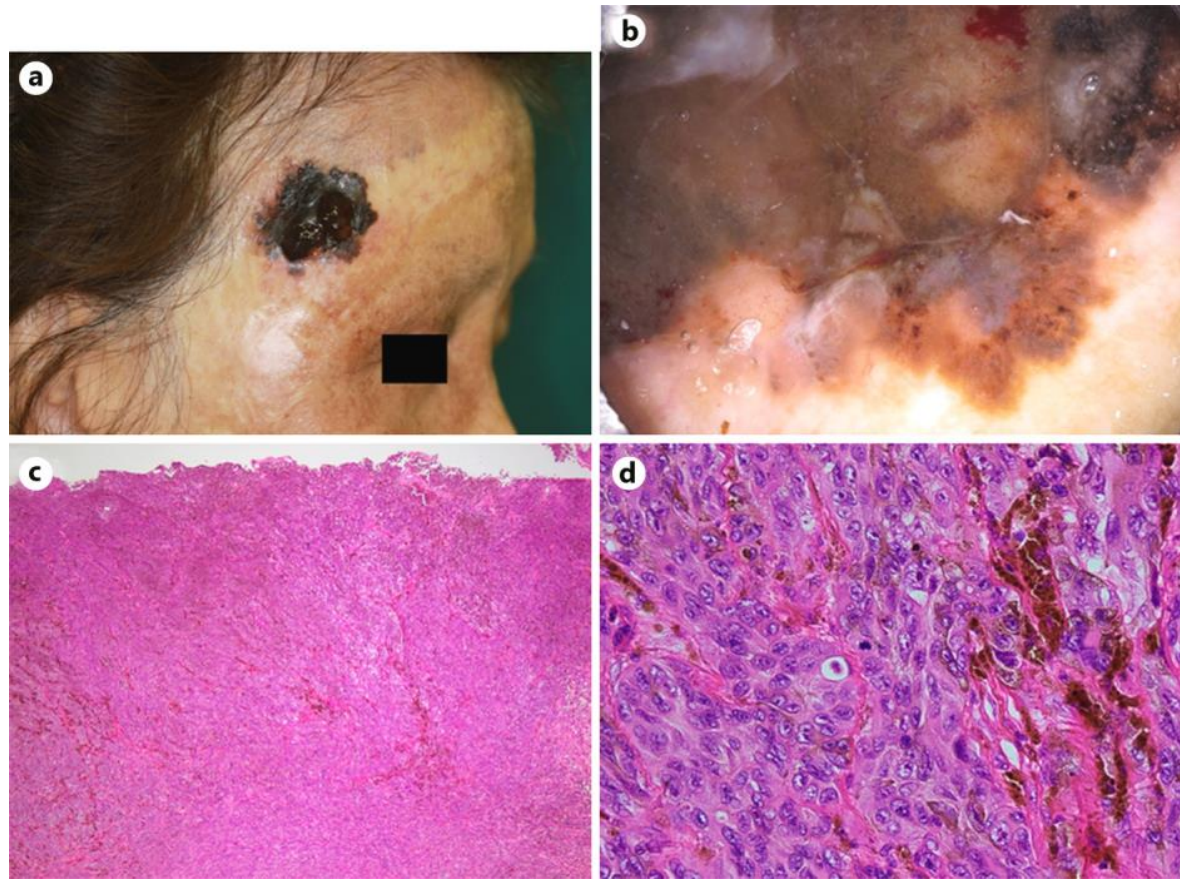

Fig. 1. a An asymptomatic blackish tumor with central ulceration, $30 \times 29 \mathrm{~mm}$ in size, on the thermal burn scar of the right forehead. b Dermoscopy showing a multicomponent pattern: irregular dots and globules, as well as blue-whitish veils and the dermoscopic islands. c Atypical cells were found in the epidermis and the dermis. Hematoxylin and eosin. $\times 40$. $d$ The cells show morphologically irregular sizes and shapes, and large hyperchromatic nuclei with pale cytoplasms. Hematoxylin and eosin. $\times 400$. 